\title{
DIREITOS HUMANOS, MÍDIA E REFÚGIO: Uma Análise sobre a Construção da Narrativa Acerca dos Migrantes Venezuelanos no Brasil
}

\author{
Denise Mercedes Nunez Nascimento Lopes Salles \\ Autora correspondente. Universidade Católica de Petrópolis. Rua Barão do Amazonas, 124 - Centro. Petrópolis/RJ, Brasil. \\ http://lattes.cnpq.br/1594102305404307. https://orcid.org/0000-0002-0062-4740 CEP 25685-100. denise.salles@ucp.br \\ Flávia Rodrigues de Castro \\ Pontifícia Universidade do Rio de Janeiro. Rio de Janeiro/RJ, Brasil.
}

Gustavo do Amaral Loureiro

Universidade Federal de Minas Gerais - UFMG. Brasil.

RESUMO

Este estudo parte do interesse sobre a imagem dos venezuelanos no Brasil, muitos dos quais escolheram dar entrada em solicitações de refúgio. Temos como objetivo a análise da representação midiática sobre os venezuelanos que cruzaram a fronteira norte do Brasil nos últimos anos, partindo de um caso específico como forma de suscitar discussões não só sobre a representação como uma forma de poder, mas também sobre injustiça por meio da operação de preconceitos identitários e estereótipos. Teoricamente, partimos da relação entre a política da piedade, tal como definida por Luc Boltanski (1999), e a visão ambivalente operada nas representações de refúgio e migração forçada. A metodologia compreende pesquisa empírica com a análise do período de agosto de 2018 que tem como referência os últimos ataques de brasileiros aos venezuelanos em Roraima. Para tanto, selecionamos três dos jornais de maior circulação no país, a saber: O Globo, Folha de São Paulo e Estadão, e sugerimos a realização de uma análise de conteúdo sobre os principais discursos articulados em torno da figura dos venezuelanos no período em estudo. Como resultado da análise, observamos que os confrontos entre venezuelanos e brasileiros, o aumento da criminalidade e da violência e os atentados de natureza xenófoba são tratados na mídia de forma que remete à ameaça para a segurança pública e fragilização do Estado brasileiro e não com um olhar focado na garantia de direitos humanos dos venezuelanos que recorrem ao país em busca de condições de sobrevivência.

Palavras-chave: refugiados; mídia; venezuelanos; política da piedade.

\section{HUMAN RIGHTS, MEDIA AND REFUGE:}

AN ANALYSIS OF THE CONSTRUCTION OF THE NARRATIVE ABOUT VENEZUELAN MIGRANTS IN BRAZIL ABSTRACT

This study is based on an interest in the image of Venezuelans in Brazil, many of whom chose to request refugee status. The objective of this paper is to analyze the media representation about the Venezuelans who crossed the northern border of Brazil in recent years, starting from a specific case as a way of prompting discussions not only about representation as a form of power, but also about injustice through the operation of identity biases and stereotypes. Theoretically, we start from the relations between the politics of pity, as defined by Boltanski (1999), and the ambivalent view of the representations of refugee and forced migration. The methodology comprises empirical research with the analysis of the period of August of 2018 as a reference to the last attacks on Venezuelans in Roraima. To do so, we selected three of the most widely circulated newspapers in the country, namely: O Globo, Folha de São Paulo and Estadão, and propose a content analysis on the main discourses articulated around the figure of the Venezuelans in the period under analysis. As a result of the analysis, we observe that the confrontations between Venezuelans and Brazilians, the increase of crime and violence and the attacks of a xenophobic nature are treated in the media in a way that refers to the threat to public safety and the weakening of the Brazilian State; and not with a focus on guaranteeing the human rights of Venezuelans who resort to the country in search of survival conditions.

Keywords: refugee; media; venezuelan; politics of pity. 


\section{INTRODUÇÃO}

A figura do refugiado pode ser pensada por meio de uma série de processos sociológicos e burocráticos que operam de forma a constituir a imagem de quem é um sujeito em situação de refúgio. Nesse sentido, antes de pensar o refugiado como uma condição ontológica, dada a priori, e revelada mediante processos de determinação do status, é importante refletir sobre as diferentes formas pelas quais a figura do refugiado é constantemente (re)construída. Apesar das possibilidades distintas de análise, optamos neste artigo por uma investigação que parte do interesse sobre as representações midiáticas da figura do refugiado. De forma mais específica, procuramos analisar a exposição midiática a respeito do fluxo de venezuelanos que cruzaram a fronteira norte do Brasil - muitos dos quais escolheram dar entrada em solicitações de refúgio no território brasileiro. ${ }^{1}$ Cabe ressaltar, assim, que faremos uso da categoria do refúgio a partir da inclusão nesta daqueles considerados solicitantes e, portanto, que ainda não tiveram seu status de refugiado reconhecido.

Temos como objetivo, então, a análise da representação midiática sobre o fluxo de venezuelanos que cruzaram a fronteira norte do Brasil, partindo de um caso específico como forma de suscitar discussões não só sobre a representação como uma forma de poder, mas também sobre injustiça por meio da operação de preconceitos identitários e estereótipos. Buscaremos, assim, analisar o período de um mês (agosto de 2018) que tem como referência os últimos ataques aos venezuelanos em Roraima. ${ }^{2}$ Para tanto, selecionamos três dos jornais de maior circulação no país (O Globo, Folha de São Paulo e Estadão) e propusemos a realização de uma análise de conteúdo sobre os principais discursos articulados em torno da figura dos venezuelanos no período em estudo. Entendemos aqui a importância do uso da linguagem em processos constitutivos e partimos da premissa de que a sua utilização pode ajudar a manter ou desafiar discursos ou ideologias particulares sobre o mundo e as coisas. É nesse sentido também que partimos inicialmente da crítica à imagem ontológica da figura do refugiado e a percebemos como um processo de construção. Conforme adverte Foucault, discursos são práticas que sistematicamente formam os objetos dos quais falamos.

Faremos uso no artigo de uma análise de conteúdo que pode ser mais bem especificada como análise corpora, isto é, análise de um conjunto de textos digitalizados que constituem uma amostra representativa do fenômeno investigado. Cabe salientar que aquilo que chamamos de corpora é visto como um repositório de linguagem amplo o suficiente para revelar repetições ou padrões que podem ser sugestivos em relação a traços do discurso. Ainda que haja discordâncias sobre corpora como uma metodologia ou como uma teoria da linguagem

\footnotetext{
Número de solicitações de refúgio de venezuelanos Segundo o Informe do Conare de 2018: 35.540 até o primeiro semestre de 2018.. Cf: https://oglobo.globo.com/brasil/pedidos-de-refugio-de-venezuelanos-no-brasil-dobraram-em-seis-meses-22893216.

2 Em 17 de agosto de 2018 um comerciante de Pacaraima foi agredido e espancado e o ato foi atribuído a venezuelanos. Com isso, teve início um acirramento da violência na qual moradores da região se revoltaram contra os venezuelanos que buscam abrigo na cidade. "Refugiados venezuelanos foram atacados por brasileiros em Roraima. Moradores de Pacaraima destruíram acampamentos, bloquearam a fronteira e expulsaram imigrantes do Brasil. A tensão começou no início da manhã deste sábado (18). Com bombas caseiras e pedaços de pau, moradores de Pacaraima destruíram abrigos improvisados. Uma venezuelana teve documentos e objetos queimados e agora não sabe o que fazer. Imigrantes foram obrigados a deixar a cidade". Disponível em: https://g1.globo.com/jornal-nacional/noticia/2018/08/18/ abrigo-de-venezuelanos-e-atacado-em-roraima-apos-assalto-a-comerciante.ghtml
} 
(ou ambos), o importante aqui é deixarmos claro que ela pode ser pensada como uma análise de um corpo (usualmente referido como corpus) de linguagem amplo e representativo, realizada a partir de softwares que ajudam o pesquisador a interpretar seus arquivos de texto. Apesar da necessidade de ferramentas computadorizadas específicas para fins de realização da análise, consideramos a presença subjetiva do pesquisador em todas as etapas do processo - desde a escolha e montagem do corpus, passando pela leitura e interpretação dos dados, até as conclusões e hipóteses daí derivadas. Temos, assim, a combinação de técnicas quantitativas e qualitativas de pesquisa, o que pode ajudar a trazer para o processo as potencialidades de ambas.

A escolha de um período de tempo específico em torno de um episódio recente e marcante no acolhimento aos venezuelanos na Região Norte do país justifica-se pelo interesse teórico em uma análise não somente sobre a representação como uma forma de poder (que poderia envolver uma análise geral sobre venezuelanos na mídia brasileira), mas sobre a injustiça por meio da operação de preconceitos identitários e estereótipos. Assim, neste trabaIho, como proposto por Shanahan, McBeth e Hathaway (2011), enxergamos a centralidade das narrativas na vida política. Tais discursos são construídos com o intuito de influenciar a opinião pública, moldando percepções e identidades e podendo ser apresentados de diversas formas, inclusive como notícias e editoriais publicados por jornais e revistas.

O texto divide-se em três seções, além desta introdução. A segunda seção aborda teoricamente a relação entre a política da piedade (BOLTANSKI, 1999) e a vitimização operada nas representações de refúgio e migração forçada, bem como a criminalização do migrante por meio dos discursos políticos. A terceira parte apresenta o resultado da análise de conteúdo com o objetivo de avaliar quantitativa e qualitativamente a produção de significados sobre os venezuelanos na mídia nacional e a última parte tece as considerações finais da pesquisa.

\section{A POLÍTICA DA PIEDADE E O EMUDECIMENTO DAS VÍTIMAS: Direitos Humanos e Representações de Refugiados}

Ao recuperar a análise crítica feita por Hannah Arendt sobre o desenvolvimento de uma política da piedade como consequência da Revolução Francesa, Luc Boltanski (1999) amplia o conceito e explora a diferença entre uma política da justiça e a focada na piedade.

Para Arendt, uma consequência importante da reflexão pós-Revolução foi o abandono da questão da liberdade relacionada à forma de governo que a garantisse. Na política que se depreende desta transformação a distinção primordial é entre quem sofre e quem não sofre (os afortunados). Há, portanto, um foco no espetáculo do sofrimento e em sua observação pelos outros, os "sortudos", e, assim, o centro da questão social passa a ser a observação e não a ação. Nesse sentido, a perspectiva da piedade negligencia a questão da liberdade, a qual só tem lugar, para Arendt, em um espaço público centrado na ação enquanto palavra, no debate entre iguais (ARENDT, 2010).

Boltanski relata que a política da piedade tem como consequência um distanciamento, pois generaliza aqueles que sofrem e os separa dos demais, tornando-os uma massa disforme. Nessa perspectiva são reforçadas as diferenças, as quais aparecem como estáticas e não há um questionamento da justiça ou injustiça que envolve a produção da diferença. $O$ sofri- 


\section{Democracia}

mento do outro é tratado a distância; reforça-se a percepção de que a vítima, merecedora de piedade, é incapaz de sair dessa condição.

A novidade da figura da "piedade" é a da distância que se interpõe necessariamente entre o sofredor e os que se dão conta de seu sofrimento. (...) A "questão humanitária" moderna transporta o problema clássico do "bom samaritano" para um patamar diferente de engajamento e negociação. A sua transformação em uma "política" exige que o sofrimento seja tratado "a distância", pois ele visa à "generalização" (que ocupa o lugar da "universalização" no jargão empirista). Mas, ao mesmo tempo, não pode prescindir da referência e evocação do "sofrimento" efetivo - preferencialmente coletivo - a partir do qual desenvolve sua panóplia discursiva e institucional (DUARTE, 1996, p. 165).

No contexto da ajuda humanitária internacional, Boltanski questiona a atuação das ONGs, e também da mídia, uma vez que estas Organizações Não Governamentais acabam atuando como intermediadoras entre o sofredor, objeto de piedade e o espectador que se mobiliza por intermédio da visão do sofrimento do outro, reiteradamente explorada pelas mesmas organizações e pela mídia. A questão é que o trabalho de mobilização do sofrimento feito pelas organizações faz-se por meio de inspirar a piedade a um outro distante geográfica e moralmente, uma vez que a ideia que se reforça por trás dessa forma de representar o sofredor é a da diferença entre afortunados e vítimas, e não a aproximação entre, por exemplo, pessoas com igual dignidade e direitos.

Assim, a política da piedade tem diferenças fundamentais com uma política da justiça. Isso porque esta última distingue os grandes e os pequenos e suas disputas, apoia-se na meritocracia e pressupõe um consenso acerca do justo. $O$ administrador da cidade, na visão da política da justiça, empenha-se em resolver as disputas com base no princípio da equivalência e em critérios consensuais. Já na política da piedade os desafortunados são tornados massa para separá-los dos demais e inspirar a piedade. Assim, o foco da ação é a forma de acabar com o sofrimento destes que são apenas objeto da ação dos afortunados, o que negligencia as questões de justiça relativas aos sofredores e à produção do sofrimento (BOLTANSKI, 1999).

Prem Kumar Rajaram (2002) também faz uma reflexão crítica com relação ao modo como as agências humanitárias retratam os refugiados, muitas vezes os relegando a serem massas sem rosto nem voz própria. O autor ressalta que toda generalização sem cunho político bem como as narrativas que retratam os refugiados como vítimas indefesas, apenas agrupando histórias semelhantes, por exemplo, obscurecem a individualidade de cada uma das pessoas que buscam refúgio. O resultado do crescente humanitarismo e da forma de atuação da mídia é que os refugiados têm negado o direito a representar suas narrativas e aparecem, massificados, como vítimas mudas.

Malkki mostra como ocorre uma objetificação das experiências dos refugiados na caracterização destes como grupo que foi privado de suas fronteiras em um contexto histórico singular e reduzidos a normas e nomenclaturas relevantes apenas do ponto de vista do Estado. Assim, o refugiado, aquele que não tem mais cidadania, é emudecido e, portanto, necessita de alguém para falar por ele, o que, por sua vez, reforça o imaginário político que tem por centro o Estado. Este discurso de reduzir o refugiado a uma fisicalidade muda, segundo Malkki, ocorre para reforçar a sensação de humanidade universal e primordial, tratando os 


\section{Democracia}

refugiados como vítimas universais, o que dificulta enxergar que há indivíduos por trás dessas massas (MALKKI, 1996 apud RAJARAM, 2002, p. 248).

Como também ressalta Boltanski, toda essa objetificação evoca um sentimento de pena e empatia que tem como substrato uma "humanidade universal". Este arquétipo torna-se, então, pronto para ser utilizado para outros propósitos, como fraudes e esquemas para angariar fundos, bem como para a propaganda do Estado "acolhedor".

Importa salientar que Rajaram (2002) propõe uma forma de atuação diferenciada para as organizações humanitárias com o propósito de evitarem o emudecimento e a universalização objetificada da figura do refugiado. Para tanto, o autor reconhece que, como a identidade é uma produção, um novo humanitarismo pode surgir a partir do entendimento das necessidades pessoais dos refugiados e do reconhecimento de que eles são pessoas com suas histórias, desejos e cultura, assim como direitos. Afastar-se, portanto, das narrativas de vitimização e da exploração da imagem de mulheres e crianças, que reforçam a visão do refugiado como indefeso, é um caminho, assim como dar voz aos próprios refugiados.

O estudo quasi-experimental realizado por Shanahan, McBeth e Hathaway (2011) revela que, na turbulenta arena política em que indivíduos são expostos a incontáveis volumes de informações e assuntos, o discurso midiático pode exercer grande influência sobre a opinião pública, oferecendo à audiência elementos narrativos que auxiliem na interpretação de um determinado problema ou tópico a ser discutido. Dessa forma, narrativas são capazes de oferecer explicações ao público e, ao mesmo tempo, permitir que os indivíduos as interpretem e absorvam de formas particulares, desenvolvendo certa compreensão sobre como o mundo ou a sociedade em que estão inseridos deve progredir e qual seria seu papel a desempenhar neste processo (BRUNER, 1996; PATTERSON; MONROE, 1998).

Essas narrativas políticas são capazes de fortalecer opiniões alinhadas ao discurso propagado pelos veículos midiáticos e, simultaneamente, converter vozes divergentes ao oferecer um contraponto. A força desses discursos dependerá, principalmente, da capacidade de persuasão da narrativa em questão, ao se apropriar de certos elementos narrativos que podem torná-la mais atrativa ao público. A constituição de uma narrativa forte não se limita a identificar um problema, mas também desenha identidades e papéis para os atores inclusos nela, como a adoção de heróis e vilões e uma dramatização apropriada dessa dicotomia ou confronto. Em certos casos, pesquisas no campo da Psicologia indicam que narrativas políticas são capazes de exercer maior influência sobre a opinião pública do que fatos científicos, mostrando a capacidade que estas dramatizações possuem para moldar as percepções dos indivíduos e, em maior escala, da sociedade como um conjunto (SHANAHAN; MCBETH; HATHAWAY, 2011).

No contexto do refúgio diversos atores são mobilizados no discurso midiático em que a figura dos migrantes e refugiados é constantemente (re)construída de acordo com os interesses e com o poder em jogo.

No campo jurídico internacional os direitos civis e sociais dos migrantes, estrangeiros e naturalizados estão cada vez mais protegidos no mundo por meio de documentos internacionais de direitos humanos desde a Declaração Internacional dos Direitos Humanos, de 1948. No campo dos direitos políticos e da efetivação dos direitos individuais e sociais, no entanto, a realidade ainda é muito distante do marco legislativo. Como assinala Benhabib (2012), esses 
avanços acabaram gerando paradoxalmente uma exclusão ainda maior dos refugiados e dos requerentes de refúgio, que acabam não sendo beneficiados pela difusão dessas normas cosmopolitanas.

Assim, os migrantes indesejados são usados, em muitos países, como mão de obra barata, vistos como possíveis "terroristas" e, cada vez mais, considerados "inimigos" do Estado, visão que veio sendo (re)construída de forma complementar pela forma como a mídia retrata os refugiados, e, principalmente, pela atuação de políticos, que tornaram os migrantes objeto da política: especialmente para isentar o Estado da provisão de bens e serviços aos seus nacionais, com o discurso de que os imigrantes estão inchando os serviços públicos e o mercado de trabalho, e é isso que não permite que o Estado garanta direitos sociais e econômicos básicos a todos (JAROCHINSKI SILVA; ALVES, 2017).

Nesse embate, o migrante fica cada vez mais sem proteção, pois reforça-se a centralidade da soberania estatal e da cidadania e os movimentos segregacionistas, tanto internos quanto externos, renovam o contraponto com as normas internacionais de direitos humanos (BENHABIB, 2012).

O respeito aos direitos humanos e a preocupação com a garantia de direitos fundamentais tornam-se secundários diante de uma perspectiva que determina os países e aqueles que eles escolhem chamar de seus como os elementos maiores a serem protegidos. Para a realização desse objetivo, tudo é permitido, desde que feito pelo Estado (JAROCHINSKI SILVA; ALVES, 2017).

Importa salientar que as categorizações em torno de sujeitos migrantes reforçam a sua separação e a exclusão. Os migrantes são vistos, muitas vezes, como ora irregulares, ora, mais grave, ilegais ou clandestinos. Como irregular ou ilegal o imigrante não pode utilizar os serviços oferecidos pelo Estado em que se encontra, o que acaba por deixá-lo em situação frágil, posto que, sem proteção, o imigrante não encontra outra forma de sobrevivência a não ser por meio da aceitação de empregos em condições precárias com salários injustos, tornando-se assim, "vítimas de um sistema cada vez mais institucionalizado de exclusão e desumanização" (JAROCHINSKI SILVA; ALVES, 2017, p. 113).

A determinação de um estrangeiro como imigrante parte de uma decisão política, que leva em consideração inúmeros critérios sociais, econômicos e culturais, mas que se encontra intimamente carregada de uma percepção em que a imigração é vista como um problema e não como um direito (Guild, 2009, p. 14). Migrar é um direito humano fundamental, que consta na Declaração Universal dos Direitos Humanos (nos artigos 13 e 14) da Organização das Nações Unidas, de 10 de dezembro de 1948. (...) A realidade que se impõe, no entanto, muitas vezes desconsidera esses direitos e trata o imigrante como um elemento ameaçador e criminoso. Principalmente se ele se encontra em situação migratória irregular (JAROCHINSKI SILVA; ALVES, 2017, p. 115).

A criminalização do migrante e seu tratamento como inimigo, bem como sua consequente marginalização da sociedade, estão associados ao processo de reafirmação da soberania do Estado. É este quem decide quem é cidadão, detentor de direitos, e quais aqueles que, não compartilhando do direito a ter direitos (ARENDT, 2010) serão banidos da sociedade e não terão acesso a serviços básicos e à liberdade. A partir de justificativas baseadas em ques- 
tões de segurança, o Estado criminaliza o migrante para reforçar seu poder soberano (JAROCHINSKI SILVA; ALVES, 2017; BENHABIB, 2012).

\section{OS VENEZUELANOS NA MÍDIA BRASILEIRA: UMA ANÁLISE DA PRODUÇÃO DE SIGNIFICADOS}

A análise corpus da pesquisa contou com artigos de texto do Estadão, Folha de São Paulo e O Globo, no mês de agosto de 2018 , a fim de que fosse possível analisar os padrões de representação de parte significativa da mídia brasileira em relação aos venezuelanos no país, especialmente no momento em que episódios de violência e xenofobia foram praticados contra tal população na fronteira norte. Para tanto, fizemos uso de um software chamado AntConc, que permitiu a análise e interpretação de 55 artigos, com um total de 53.595 palavras. O termo de busca utilizado foi "venezuelan*", que abarca o termo "venezuelano" em suas variações (venezuelano(a)(s)), com um total de aparição nos textos do material da pesquisa de 491 vezes. Apesar de o software empregado permitir a adoção de técnicas quantitativas cruciais, como contagem de frequências, cabe ressaltar que também é fundamental o uso de técnicas qualitativas, uma vez que os pesquisadores devem interpretar as frases e palavras em seus contextos. Dessa maneira, ressaltamos aqui o papel central dos pesquisadores na análise dos dados e informações, com a sua participação em investigações manuais e detalhadas das chamadas linhas de concordância, isto é, as frases que contêm o termo de busca pesquisado.

Em um primeiro momento, fizemos uso de um corpus de referência de tamanho similar, porém sobre um tema distinto, a fim de que fosse possível gerar a chamada keyword list, isto é, a lista de palavras-chave do corpus da pesquisa. Somente a partir do emprego do corpus de referência podemos visualizar as palavras e termos que aparecem de forma central nos arquivos com os quais trabalhamos, sendo possível ordená-los por ordem de frequência. Assim, a Tabela 1 traz os resultados das palavras-chave mais frequentes no corpus da pesquisa:

Tabela 1 - Keyword List por Frequência

\begin{tabular}{lc}
\hline Keyword & Frequência \\
\hline Venezuelanos & 396 \\
Roraima & 277 \\
Governo & 264 \\
Fronteira & 202 \\
Pacaraima & 165 \\
Imigrantes & 131 \\
Crise & 113 \\
Refugiados & 100 \\
\hline Total & 1.517 \\
\hline
\end{tabular}

Fonte: Os autores. 
Por meio da lista de palavras-chave é possível constatar, de início, a alta frequência de termos que chamam a atenção para a fronteira norte do país, onde se encontra grande parte dos venezuelanos (mesmo após início de um processo de interiorização voluntária de tais sujeitos). Da mesma maneira, temos referências frequentes ao governo, à ideia de crise e aos termos "imigrantes" e "refugiados", o que poderia indicar preocupações com a ação governamental a ser tomada diante do cenário caótico do fluxo de pessoas em busca de refúgio no país ou de melhores condições de vida. Uma análise mais aprofundada, porém, só é possível a partir de outros instrumentos e técnicas de pesquisa que iremos abordar nas próximas páginas.

Após a análise e produção da keyword list, fizemos uso de uma ferramenta essencial que aborda a chamada collocation. Por meio dessa abordagem é possível identificar os termos que coocorrem no material da pesquisa, podendo apresentar padrões na forma como determinado tema é exposto. Nesse sentido, uma relação frequente entre os termos "imigrante" e "ilegal", por exemplo, produzem o collocate "imigrante ilegal", que traz consigo uma forma particular de representar o fenômeno da imigração. Tendo isso em mente, produzimos uma lista dos principais collocates associados à direita e à esquerda do nosso termo de busca, "venezuelan*", analisando as construções mais frequentes em termos de representação desses sujeitos. A Tabela 2 a seguir expõe os resultados encontrados:

Tabela 2 - Collocates por Frequência

\begin{tabular}{lc}
\hline Collocates & Frequência \\
\hline Imigrantes & 37 \\
Roraima & 31 \\
Mil & 27 \\
Refugiados & 26 \\
Fronteira & 16 \\
Entrada & 14 \\
Crise & 10 \\
\hline Total & $\mathbf{1 6 1}$ \\
\hline
\end{tabular}

A lista dos principais collocates por frequência no corpus da pesquisa aponta para a similaridade com a lista de palavras-chave já abordada anteriormente, com a ressonância de termos relacionados à situação na fronteira norte do país e o emprego do vocabulário da crise. Além disso, podemos visualizar aqui referências à quantidade de venezuelanos e ao seu movimento de entrada e cruzamento de fronteiras. O termo "imigrantes" aparece de maneira mais frequente em comparação ao termo "refugiados", o que poderia indicar uma determinada tendência na representação dessas pessoas no que diz respeito ao seu status migratório. A fim, no entanto, de realizar interpretações mais aprofundadas, propomos a seguir uma análise menos quantitativa e mais qualitativa, a partir da observação detalhada das linhas de concordância do material. 
A análise das linhas de concordância parte de uma interpretação manual e detalhada de cada uma das 491 frases em que o termo de busca da pesquisa aparece. De forma a tornar mais claro para o leitor o processo de análise corpus, cabe ressaltar aqui que o software utilizado apresenta o termo "venezuelan*" em destaque no centro de cada uma das frases que aparecem no material, com algumas das palavras mais próximas à direita e à esquerda do termo. Ao clicar sobre o termo de busca, o programa permite a leitura do texto completo, fazendo com que seja possível interpretar os resultados a partir da análise de um contexto mais amplo no qual o termo foi empregado. Tendo isso em mente, apresentamos a seguir os principais resultados comentados, destacando o papel subjetivo dos pesquisadores na análise qualitativa do material.

De início, cabe ressaltar que a análise da concordância no corpus fez emergir padrões de referência que indicam o uso de números para abordar o fluxo venezuelano. Dessa maneira, poderíamos pensar em uma categoria "quantidade" que aparece como fundamental na representação dos venezuelanos, indicando um alto número do êxodo populacional. Tais números são utilizados, na maior parte dos casos, para fazer referência à entrada dos venezuelanos no Brasil, bem como à quantidade abrigada em Roraima e Pacaraima, na Região Norte do país. Conforme vemos em um dos textos que comenta a situação em Pacaraima, um dos moradores afirma que "os venezuelanos tomaram conta". Também ganham destaque menções ao número de venezuelanos atendidos em estabelecimentos públicos brasileiros e o que este quadro causaria de incômodo à população brasileira em termos de superlotação em atendimento e prestação de serviços. Conforme é possível perceber em um dos textos: "O maior impacto foi na saúde. No Hospital Geral de Roraima, o número de atendimentos a venezuelanos subiu 2.643\%". De maneira geral, há referências constantes à entrada diária de um número elevado de venezuelanos - um cenário que é contraposto à falta de infraestrutura em Roraima para recebê-los. Além disso, é feita uma comparação entre o número de brasileiros e venezuelanos atendidos pelo poder público, com a afirmação de que: "De janeiro a junho, foram atendidos mais venezuelanos do que brasileiros nas unidades básicas de saúde da cidade de Boa Vista".

Ainda no contexto da categoria "quantidade", é possível identificar padrões de referência à situação de desemprego vivida pelos venezuelanos no norte do Brasil, ao seu estado de (des)alojamento, tendo em vista suas moradias improvisadas (muitas vezes em ruas e calçadas), bem como à atuação de alguns venezuelanos como pedintes nas ruas. Em um dos textos compilados pela pesquisa, um morador de Roraima afirma que: "Em qualquer supermercado ou serviço público tem venezuelanos abordando as pessoas, pedindo dinheiro". Em outro trecho que faz menção à Boa Vista, lemos que: "Agora, a cidade de 320 mil habitantes convive com 30 mil venezuelanos, sendo que 2.000 dormem nas calçadas, ao relento, e os outros moram em abrigos ou espremidos em quartos alugados insalubres". Convidada a comentar as afirmações, a prefeita de Boa Vista, Teresa Surita (MDB), afirma: "As pessoas reclamam muito porque elas perderam os seus espaços". Neste contexto quantitativo que reforça a imagem da crise, também vemos referências constantes à falta de medicamentos em razão do elevado número de atendimentos a venezuelanos, assim como à proliferação de doenças trazidas pelo fluxo populacional: "O sarampo, que havia sido eliminado, voltou. Até 10 de agosto, Roraima já tinha 296 casos confirmados, sendo 201 de venezuelanos". 


\section{Democracia}

Os números aparecem, assim, como referências constantes em alguns cenários específicos: para relatar a entrada de venezuelanos no Brasil, para mencionar a superlotação causada em instituições públicas, para indicar novos surtos de doenças trazidas pela população da Venezuela e para retratar a falta de estrutura para receber estes fluxos novos. Nesse sentido, ter de lidar com a situação de espólio e escassez na qual se encontram os venezuelanos que chegam ao país emerge como um incômodo para os brasileiros. Ao mesmo tempo, o desafio do relacionamento com a alteridade, com este "outro espoliado", é tratado por lideranças políticas do país como um sentimento de "perda de espaço" por parte dos brasileiros. Não foram encontradas referências, porém, à responsabilidade dos órgãos públicos na formulação de políticas e criação de estruturas para atender às necessidades daqueles que chegam, fugindo de um cenário de violência e privação de direitos humanos que ocorre na Venezuela.

Os padrões de representação não envolvem somente a categoria "quantidade", abordada nos parágrafos anteriores, mas também uma categoria que poderíamos chamar de "crise". Assim, a referência à situação venezuelana traz não apenas números e porcentagens, mas também um vocabulário da crise, o qual é, em grande medida, reforçado pela imagem dos grandes números. Temos, então, padrões de referência à crise venezuelana como a "maior crise humanitária que o Brasil já enfrentou". A crise também é constantemente mencionada como uma crise pontual, em Roraima, corroborando as ideias anteriores trazidas pela utilização dos números para retratar uma realidade caótica na fronteira norte. Termos usados de maneira frequente no material compilado também fazem referência à "crise migratória" como problema a ser solucionado pelo governo brasileiro. De forma menos acentuada, temos referências à crise como um conflito que ocorre na Venezuela, em razão da situação política e econômica no país. O padrão de representação, porém, traz a ideia de uma crise migratória da perspectiva brasileira, isto é, que afeta primordialmente o país que recebe o fluxo de venezuelanos. Assim como ocorre de forma geral no discurso da crise dentro do campo do refúgio e das migrações, a perspectiva comumente empregada é dos países que deveriam receber os fluxos migratórios - apenas em menor medida vemos referências à crise a partir da perspectiva dos países de origem dos imigrantes e refugiados.

O quadro de crise também é articulado à relação entre brasileiros e venezuelanos, com frequentes menções aos ataques xenófobos contra os imigrantes e refugiados da Venezuela. Tal quadro, porém, é retratado em um cenário maior no qual a própria relação entre os nacionais e os imigrantes é questionada, com a exposição de relatos de violência e crimes supostamente provocados por venezuelanos. Nesse sentido, atos de xenofobia são representados como parte dos embates entre os dois grupos, conforme lemos: "Pacaraima se transformou em uma zona de conflitos entre brasileiros e venezuelanos neste sábado (18)." Algumas manchetes afirmam, então, que "venezuelanos e brasileiros se confrontam em Roraima". Os textos passam a trazer, assim, relatos de brasileiros que teriam sido agredidos por venezuelanos e que afirmam que haveria grupos de brasileiros cercados pelos imigrantes. Mais relatos afirmam que "a cidade está um caos". O contexto caótico, porém, não é atribuído a atos de violência contra venezuelanos, mas ao elevado número de pessoas em um local sem estrutura para recebê-los, o que estaria levando ao conflito entre os grupos.

Por último, mas não menos importante, é possível identificar padrões de representação que trazem discursos sobre o cenário de crise no norte do país como algo que deveria 


\section{Democracia}

impulsionar medidas restritivas aos fluxos dessa população venezuelana. Em alguns textos, após as notícias sobre o "confronto entre brasileiros e venezuelanos", há menções à fala de autoridades políticas sobre a suposta necessidade de suspender temporariamente o ingresso dos imigrantes e refugiados, com o fechamento da fronteira. É trazido, então, o discurso do senador Romero Jucá (MDB-RR) sobre sua proposta, encaminhada ao presidente Temer, de fechamento temporário da fronteira de Roraima com a Venezuela, especialmente em Pacaraima. Segundo ele: "Tenho discutido uma solução para essa questão da migração desenfreada em Roraima, estudei soluções que estão sendo feitas no mundo todo". Parte da solução, no entendimento de Jucá, seria o estabelecimento de cotas para venezuelanos no Brasil. Dessa maneira, a fim de lidar com o cenário de crise, conforme relatado nos parágrafos anteriores, parte da solução proposta é impedir o fluxo de venezuelanos que buscam refúgio e melhores condições de vida no Brasil. Novamente não vemos discussão sobre a formulação de políticas públicas para atender não só à população local de brasileiros, melhorando seu acesso aos serviços públicos, mas também aos venezuelanos que buscam abrigo no país.

\section{CONSIDERAÇÕES FINAIS}

Neste artigo trabalhamos com uma perspectiva analítica para decompor a construção de um discurso que emudece e massifica "os venezuelanos" que buscam refúgio no país. Sob esse viés, não há espaço para a voz dos migrantes e suas histórias pessoais são continuamente construídas e reforçadas por meio do olhar único lançado sobre eles pela mídia nacional, o qual não parte da construção que os migrantes fazem de sua história e de sua realidade social e política, mas sim da categorização do venezuelano que cruza a fronteira feita de forma despersonalizada, criminalizatória e excludente.

Ao inserir esta discussão aos estudos sobre refúgio, podemos observar, assim como destacado por Rajaram (2002), que há uma tendência das agências humanitárias internacionais de representar os refugiados como massas de vítimas e pessoas que sofrem enormes perdas, o que, de uma certa forma, os emudece e nega seu direito de apresentar suas próprias narrativas. Esse olhar, por sua vez, é encampado por um discurso político que toma o migrante como objeto para a política, e, assim, opõe os migrantes aos nacionais, identificando-os como vilões, ameaças potenciais à segurança nacional e mesmo à capacidade do Estado em prover direitos aos seus cidadãos (JAROCHINSKI SILVA; ALVES, 2017).

Ao realizar uma análise de conteúdo nos artigos publicados por três dos jornais de maior circulação no país, é possível observar que a mídia brasileira tende a reproduzir este mesmo discurso "vilanificador" dos migrantes venezuelanos. O foco midiático na necessidade por intervenção estatal para resolver "a realidade caótica" criada pelos movimentos migratórios na fronteira com Roraima, na maioria das vezes, reflete o drama venezuelano - a vulnerabilização de seus cidadãos, que são forçados a recorrer à migração em busca de sobrevivência ou condições de vida mais adequadas - como um problema para o Brasil, que é obrigado a conviver com um fluxo migratório constante. A preocupação não parece ser, genuinamente, com o sofrimento da população migrante, mas sim com o caos que produz no território brasileiro.

Isto pode ser evidenciado com a forma em que são empregadas as constantes menções à quantidade: o desemprego, desalojamento, ocupação dos espaços e serviços públicos são ameaças à população local (aos cidadãos brasileiros), uma vez que a capacidade do Es- 
tado para garantir tais serviços para os locais estaria fragilizada, mas em poucos momentos demonstra-se uma preocupação exclusivamente voltada aos migrantes venezuelanos, que necessitariam de auxílio humanitário. Os confrontos entre venezuelanos e brasileiros, o aumento da criminalidade e da violência e os atentados de natureza xenófoba, por sua vez, são todos ilustrados de forma que remetem à ameaça para a segurança pública, fragilizando, mais uma vez, o Estado.

As referências aos conflitos são frequentemente seguidas por menções de autoridades políticas que buscam restringir o acesso destes migrantes e aumentar o controle fronteiriço. A proposta seria, então, impedir o fluxo de venezuelanos de chegar ao Brasil para não causar problemas aos brasileiros, em vez de formular políticas focadas no acesso aos serviços públicos, ao trabalho e à moradia, tanto para locais quanto para os migrantes, a fim de reduzir a situação de vulnerabilidade para ambos e, ao mesmo tempo, garantir que aqueles que são forçados a fugir de seu país de origem possam ter abrigo.

Verifica-se também que o olhar das agências humanitárias tem pouca ou nenhuma reverberação na mídia nacional, não chegando, assim, a se constituir como uma voz mobilizadora da política da piedade para com os refugiados venezuelanos.

O trabalho da mídia, como disposto no período de tempo proposto por este estudo, pareceu estar muito mais centrado na construção de uma narrativa capaz de moldar a opinião pública (SHANAHAN; MCBETH; HATHAWAY, 2011) de forma a ultrajar os migrantes venezuelanos, mesmo que indiretamente, como efeito colateral de uma oposição política ao regime político da Venezuela. Nessa ótica, o Estado deveria agir para proteger os cidadãos brasileiros destes elementos nocivos, e a intervenção estatal precisaria funcionar para reduzir a migração em vez de melhorar os serviços públicos e oferecer assistência humanitária aos mais vulneráveis.

\section{REFERÊNCIAS}

ARENDT, Hannah. A condição humana. Rio de Janeiro: Forense Universitária, 2010.

BENHABIB, Seyla. O declínio da soberania ou a emergência de normas cosmopolitanas?: Repensando a cidadania em tempos voláteis. Civitas, v. 12, n. 1, p. 20-46, Porto Alegre, 2012.

BOLTANSKI, Luc. Distant Suffering: Morality, Media and Politics. Cambridge: Cambridge University Press, 1999. BRUNER, Jerome. The Culture of Education. Cambridge: Harvard University Press, 1996.

DUARTE, Luiz Fernando D. Distanciamento, reflexividade e interiorização da pessoa no ocidente. Mana, Rio de Janeiro, v. 2, n. 2, p. 163-176, out. 1996. Disponível em: http://www.scielo.br/scielo.php?script=sci_arttext\&pid=S010493131996000200007\&lng=en\&nrm=iso. Acesso em 09 dez. 2018.

JAROCHINSKI SILVA, João C.; ALVES, L. A. Categorização, exclusão e criminalização das migrações internacionais. Revista Interdisciplinar de Direitos Humanos, v. 5, p. 111-126, 2017.

PATTERSON, Molly; MONROE, Kristen Renwick. Narrative in political science. Annual Review of Political Science, v. 1, p. 315-331, 1998.

RAJARAM, Prem Kumar. Humanitarianism and representations of refugees. Journal of Refugee Studies, 15(3): 247-264, 2002.

SHANAHAN, Elizabeth A.; MCBETH, Mark K.; HATHAWAY, Paul L. Narrative Policy Framework: The Influence of Media Policy Narratives on Public Opinion. Politics \& Policy, v. 39, n. 3, 2011, p. 373-400. 